\title{
O Acesso à Justiça como Direito Humano Fundamental: Retomada Histórica para Se Chegar à Concepção Atual
}

\author{
Access to Justice as a Fundamental Human Right: Historical Recovery to \\ Arive at the Current Design
}

\begin{abstract}
QUELI CRISTIANE SCHIEFELBEIN DA SILVA
Mestranda em Direitos Humanos pela Unijuí, Pós-Graduada em Ciências Penais pela Universidade do Sul de Santa Catarina em 2009, com Área de Conhecimento em Direito Penal, Graduada em Direito pela Universidade Regional do Noroeste do Estado do Rio Grande do Sul em 2007, Servidora Pública Federal, Técnica Judiciária da Justiça Federal de $1^{\circ}$ Grau da Seção Judiciária do Rio Grande do Sul, Subseção de Santo Ângelo, desde 2006, Supervisora do Jefa de ljuí desde sua Inauguração, em 2010, Nomeada Instrutora-Conciliadora em 2010 , Atuando Junto às Audiências do Jefa de ljuí, Integrante do Projeto Estratégico de Ampliação do Acesso à Justiça - Planejamento Estratégico da Justiça Federal da Seção Judiciária do Rio Grande do Sul.
\end{abstract}

Submissão: 19.10 .2012

Decisão Editorial: 27.11.2012

RESUMO: 0 presente artigo busca demonstrar 0 acesso à Justiça como um direito humano fundamental, podendo ser visto como o mais básico dos direitos humanos, pois é garantidor de todos os demais direitos. Para se chegar à concepção atual do acesso à Justiça, é importante fazer uma retomada histórica do seu conceito, o que redunda em uma breve retomada histórica dos direitos humanos, para se verificar como ele foi evoluindo nas declarações e tratados de direitos. Nesse sentido, são verificados os marcos de evolução do acesso à Justiça desde a antiguidade até as declarações e tratados atuais para se chegar no conceito que hoje se utiliza para o termo, ou seja, como um direito fundamental à efetiva prestação da justiça.

PALAVRAS-CHAVE: Acesso à Justiça; direito humano fundamental; retomada histórica.

ABSTRACT: This article seeks to demonstrate the access to justice as a fundamental human right, may be seen as the most basic human rights because it is the guarantor of all other rights. To get to the current concept of access to justice, it is important to resume its historical concept, which leads to a brief historical resume of human rights, to see how it has evolved in treaties and declarations of rights. In this sense the landmarks are checked for changes in access to justice from antiquity to the present treaties and declarations to get the concept that today is used for the term, that is, as a fundamental right to effective delivery of justice.

KEYWORDS: Access to justice; fundamental human right; resumption of history.

SUMÁRIO: Introdução; 1 Marcos históricos da evolução do acesso à Justiça; 1.1 Grécia e Roma antigas; 1.2 Contribuição do cristianismo; 1.3 Cartas e declarações inglesas; 1.3.1 A Magna Carta; 
1.3.2 A petição de direitos; 1.3.3 Lei de habeas corpus; 1.3.4 Declaração de Direitos; 1.4 A contribuição da Reforma Protestante; 1.5 A Declaração de Virgínia; 1.6 A declaração de direitos norte-americana; 1.7 A declaração dos direitos do homem e do cidadão; 1.8 A Carta das Nações Unidas; 1.9 A Declaração Universal dos Direitos Humanos; 1.10 Convenções e pactos de direitos humanos; 1.10.1 A Convenção Europeia dos Direitos Humanos; 1.10.2 Os Pactos Internacionais de Direitos Humanos de 1966; 1.10.3 A Convenção Americana de Direitos Humanos; 2 Concepção atual do acesso à Justiça; Conclusão; Referências.

\section{INTRODUÇÃO}

O acesso à Justiça é entendido atualmente como um direito humano fundamental, pois é a ideia central ao redor da qual convergem todos os princípios e garantias constitucionais. Dessa forma, como garantidor de todos os demais direitos, é necessário que seja de fato garantido o acesso a uma ordem jurídica justa. Mas para uma melhor compreensão do direito de acesso efetivo à Justiça como o mais básico dos direitos humanos é importante fazer uma breve retomada histórica do mesmo, para se verificar como se deu o nascimento e evolução desse direito, especialmente nas declarações e tratados de direitos humanos, para se chegar a concepção atual.

Para fins de cumprir com tais objetivos, o método de abordagem utilizado foi o dedutivo, partindo da relação entre argumentos gerais, denominados premissas, para argumentos particulares, até se chegar a uma conclusão. Como método de procedimento, foi utilizado o método monográfico, a partir de pesquisas e fichamentos em fontes bibliográficas, estudo de estatísticas ligadas ao tema da pesquisa, além de livros e trabalhos relativos ao assunto (Ventura, 2000).

\section{MARCOS HISTÓRICOS DA EVOLUÇ̃̃̃O DO ACESSO À JUSTIÇA}

$\mathrm{O}$ acesso à Justiça é reconhecido atualmente como um direito humano fundamental, e, dessa forma, pressuposto para o exercício da cidadania, pois a concretização dos demais direitos fundamentais é inviável sem o acesso à Justiça, razão pela qual pode ser chamado de direito a ter direitos. Mas seu reconhecimento não foi sempre assim, sendo que evoluiu ao longo dos tempos. Nesse sentido, apesar de bastante limitadas, foi na Antiguidade Clássica que apareceram as primeiras iniciativas relacionadas com o acesso à Justiça, sendo que seu conceito foi evoluindo no decorrer da evolução dos direitos humanos, o que se verá a seguir.

\subsection{GRÉCIA E Roma antigas}

Nas antiguidades clássicas, as relações sociais estavam centradas nas forças da religião e da família, sendo que naquele tempo não havia as liberdades individuais, tal como as conhecemos hoje. Ademais, tanto em Roma como na 
Grécia antigas, o Estado não encontrava limites na sua órbita de atuação. Todavia, algumas ideias sobre o conceito de democracia surgiram na Grécia antiga e depois tiveram lugar também na República Romana. Nesse sentido, segundo Carvalho:

Na Grécia, os cidadãos reuniam-se em praça pública, a ágora, para decidir sobre a vida da cidade e deliberarem sobre os negócios públicos, e daí derivaram as concepções de participação popular na formação da vontade do Estado e bem assim a ideia de limitação do poder, que é caudatária do conceito de direitos humanos. (2002, p. 33)

Já Comparato (2010, p. 53) refere que "a proto-história dos direitos humanos começa nos séculos XI e X a.C., quando se institui, sob Davi, o reino unificado de Israel, tendo como capital Jerusalém". Nesse reino, que durou 33 anos (996 a.C. a 963 a.C.), foi estabelecida pela primeira vez na história política da humanidade a figura do rei-sacerdote, ou seja, o monarca que se apresentava como delegado do Deus único e responsável supremo pela execução da lei divina. Dessa forma, não se proclamava deus nem se declarava legislador. Esse foi o embrião daquilo que, muitos séculos depois, seria designado como Estado de Direito, isto é, "uma organização política em que os governantes não criam os direitos para justificar o seu poder, mas submetem-se aos princípios e normas editados por uma autoridade superior" (Comparato, 2010, p. 54).

Todavia, o mesmo autor refere que essa "experiência de limitação institucional do poder de governo foi retomada no século VI a.C., com a criação das primeiras instituições democráticas em Atenas, e prosseguiu no século seguinte, com a fundação da República Romana" (Comparato, 2010, p. 54). Assim, foram nas instituições romanas e gregas que surgiram os primeiros elementos que contribuíram para eclodir o pensamento democrático nos séculos vindouros.

Ainda na antiguidade clássica, havia a disponibilização de advogados para a defesa dos pobres, o que demonstra uma iniciativa relacionada ao acesso à Justiça. Nesse sentido, em Atenas eram nomeados dez advogados por ano para realizar tal função e em Roma o Estado dava advogados para aqueles que não tivessem condições de pagá-los.

\subsection{ConTRIBUIÇ̄̃o do CRISTIANISMO}

A religião grega ou romana era politeísta, nutrindo-se de vários deuses, sendo que cada cidade ou polis tinha o seu Deus que era venerado e o estrangeiro era proibido de participar dos cultos domésticos. Com o surgimento do monoteísmo, passou-se a concepção de que haveria um único Deus, sendo o homem o ponto culminante da criação divina, tendo sido criado à imagem e semelhança de Deus, o que já atribuiu ao homem uma dignidade natural, sendo que os padres da igreja construíram uma doutrina que engendrou a concepção dos direitos naturais do homem. 
Ademais, como o cristianismo não pertencia a nenhuma casta, cidade ou corporação, chamou desde o início todos os povos da humanidade para serem evangelizados, conforme determinação de Cristo a seus apóstolos. Nesse sentido, estabelece-se uma ideia geral de igualdade entre todos os membros da grande família humana, sem preconceitos de raça ou cor, razão pela qual os ideais do cristianismo foram, e ainda são, para muitos, "a viga mestra sobre a qual se assenta a luta histórica pelos direitos do homem" (Carvalho, 2002, p. 35).

Salienta-se, ainda, que a doutrina cristã possui muito presente o sentimento de caridade, o que incentivou o surgimento de assistência legal aos pobres em vários países, sendo que as primeiras formas desses sistemas constituíam-se em obrigar os advogados a fazer a defesa dos pobres sem cobrar honorários, e aos juízes de julgar, sem a cobrança das custas.

\subsection{Cartas e declarações inglesas}

\subsubsection{A Magna Carta}

Observa-se, em Comparato (2010), que, no século XI, a característica política da Europa, tanto na sociedade civil quanto na eclesiástica, exprimia-se no perfil centralizador do poder, sendo que a regra que dominava à época era a divisão do império em grandes propriedades, onde para cada parte imperava a figura do senhor feudal, o qual determinava as regras que orientavam a relação política, econômica e social daquele espaço delimitado. Aquele que detinha mais força entre todos era conhecido como suserano e alcançava o posto de monarca.

Na época, a divisão da sociedade medieval era em três classes, isto é, grupos sociais interligados pelo berço com regime próprio de conduta da seguinte forma piramidal: clero, nobreza e povo. No ápice, a soberania espiritual do sacerdote, no patamar intermediário, o patriciado, responsável pela segurança coletiva, e, por fim, a base era composta pela força produtiva. Os dois primeiros detinham privilégios, enquanto o escalão inferior tinha em seu favor apenas o fato de estar alheio à condição servil das massas.

A concepção dos estamentos começou a ser desmitificada em uma ponta com a adoção do monaquismo, que envolveu no mesmo movimento as três ordens, com a finalidade de dedicação ao cultivo da terra e a ética religiosa. De outro, a revitalização urbana concebida pela retomada da navegação no Mediterrâneo deu origem a novos povoados edificados pelos comerciantes em apenso aos já existentes. Esses cidadãos não estavam compreendidos em nenhuma das três castas; portanto, logrou-se em formatar a própria burguesia, a quem não interessava a origem, e sim a condição econômica.

Nesse contexto, foi assinada, em 15 de junho de 1215, pelo Rei João da Inglaterra, também conhecido como João Sem-Terra, a oficialmente denomina- 
da Carta Magna das Liberdades ou Concórdia entre o Rei João e os Barões. A finalidade era a outorga das liberdades da igreja e do reino inglês, de natureza unilateral, sendo que constituiu o marco inicial do controle dos atos de poder pelo Direito. Portanto, a promessa real promulgada assegurou, ainda que pessoalizada, garantias para clero e barões no tocante ao respeito do monarca sobre determinadas liberdades destes e sua sujeição ao texto emanado.

Assim, sua importância histórica foi de ser o primeiro documento que buscou limitar o poder do governante, embora fosse um documento de proteção dos direitos das classes privilegiadas da sociedade medieval. Nesse sentido, Carvalho menciona que "a Magna Carta constitui o início de um movimento tendente à colocação de freios ao poder real que mais tarde gerou a doutrina do constitucionalismo e o estabelecimento dos direitos humanos" (Carvalho, 2002, p. 36).

\subsubsection{A petição de direitos}

A Petition of Rights, de 1628, é um documento dirigido ao monarca no qual os membros do Parlamento da época pediram o reconhecimento de diversos direitos e liberdades para os súditos da majestade, sendo, na verdade, um pedido de observância de direitos e liberdades já reconhecidos na própria Magna Carta. Isso porque os mandamentos não eram respeitados pelo poder monárquico, que somente com o tempo e com o crescimento e afirmação das instituições parlamentares e judiciais é que foi cedendo às imposições democráticas (Silva, 2003).

\subsubsection{Lei de habeas corpus}

O Habeas Corpus Act, editado na Inglaterra, em 1679, reforçou as reivindicações de liberdade, traduzindo-se na mais sólida garantia de liberdade individual, sendo que oficialmente denominou-se "uma lei para melhor garantir a liberdade do súdito e para prevenção das prisões no ultramar" (Comparato, 2010, p. 100). Ele foi resultado da queda de braço entre a dinastia católica dos Stuart e a maioria protestante do Parlamento buscou impor limites ao arbítrio das prisões sem o devido processo de adversários políticos.

Apesar de estar presente na legislação no formato de mandado judicial antes mesmo da Magna Carta, carecia de força coerciva diante do modelo jurídico inglês, que exige uma ação judicial para garantir o direito. Assim, consiste em ordem para apresentar o paciente à autoridade competente dentro de determinado interstício temporal, considerando a distância entre o local da segregação e a sede da jurisdição, sendo a resposta encontrada para solucionar a demora deliberada em responder os writs por parte dos funcionários da Realeza.

\subsubsection{Declaração de Direitos}

O documento mais importante da época foi chamado de Declaração de Direitos, ou Bill of Rights, sendo promulgado na Inglaterra, em 1689. 
Fazendo uma breve retomada histórica, verifica-se, em Comparato (2010), que a alta carga de impostos serviu parcialmente de pressuposto para embasar a Magna Carta, assim como no caso da Declaração de Direitos, porém, combinada com a disputa de credo religioso do herdeiro real. A dinastia Stuart tinha fortes vínculos com o catolicismo, sendo esta a religião considerada oficial. O Rei Carlos II, sem o consentimento do Parlamento, elevou as exações fiscais, orientado pelo Rei francês Luis XIV, até então inimigo da coroa inglesa. Ainda assim, a revolta foi contida. Entretanto, o nascimento do filho de Jaime II, o qual sucedeu seu irmão Carlos, legitimava a perpetuação católica no trono. A rebelião eclodiu em 1688 (Revolução Gloriosa) e o rei acabou refugiado. Em seu lugar, assumiu a irmã Maria, simpática do protestantismo. A condição para assunção do poder foi o aceite integral ao documento, ou seja, os poderes reais estavam limitados pela declaração de direitos.

Dessa forma, o advento culminou com a queda da monarquia absolutista, impondo limites ao poder de legislar e tributar que passaram a ser de responsabilidade do Parlamento, sendo que o processo representativo recebeu proteção diante da discricionariedade do soberano instituindo a clássica separação de poderes. Enfim, resultou no indício de institucionalização da organização do Estado como garantia fundamental e as liberdades individuais concedidas fortaleceram os burgueses, por conseguinte, sedimentaram as bases para a Revolução Industrial.

Assim, com a Declaração de Direitos, surge na Inglaterra a monarquia constitucional, submetida à soberania popular, que teve como seu principal teórico Locke, sendo que "serviu de inspiração ideológica para a formação das democracias liberais da Europa e da América nos séculos XVIII e XIX" (Silva, 2003, p. 153).

Registra-se, então, aproveitando os ensinamentos de Sarlet (2007), que as declarações inglesas do século XVII anteriormente mencionadas (Petition of Rights, de 1628; Habeas Corpus, de 1679; e Bill of Rights, de 1689) representaram a positivação de direitos e liberdades reconhecidos aos cidadãos ingleses. No mesmo sentido, Canotilho (2003) manifestou que a evolução destes momentos constitucionais, desde a Magna Carta de 1215 e as declarações inglesas do século XVII, conduzirá a sedimentação de algumas dimensões estruturantes da "constituição ocidental". Dessa forma, em primeiro lugar, a liberdade foi sedimentada como liberdade pessoal de todos os ingleses e como segurança da pessoa e dos bens de que é proprietário. Em segundo lugar, em razão da garantia da liberdade e da segurança, foi necessária a criação de um processo justo regulado por lei (due process of law), no qual são estabelecidas as regras disciplinadoras da privação da liberdade e da propriedade. Em terceiro lugar, as leis do país são dinamicamente interpretadas e reveladas pelos juízes, sedimentando o chamado direito comum (commom law) de todos os ingleses. 


\subsection{A contribuição da Reforma Protestante}

A Reforma Protestante, iniciada no século XV, que provocou uma guerra religiosa, dividindo a cristandade entre católicos e protestantes (evangélicos), foi relevante por registrar o início do reconhecimento da liberdade ao culto religioso. Nesse sentido, Sarlet (2007) registra que a Reforma Protestante foi de suma importância para a evolução que conduziu ao nascimento dos direitos fundamentais, pois levou à reivindicação e ao gradativo reconhecimento da liberdade de opção religiosa e de culto em diversos países da Europa. Ainda, conforme Bedin (2008), a Reforma Protestante gerou o enfraquecimento do poder da igreja e do papado e o fortalecimento do poder secular, estimulando o crescimento do Estado moderno, secular e centralizado.

Nesse contexto, é importante registrar que a Guerra dos Trinta Anos, que ocorria entre soberanos católicos e soberanos protestantes, finda por meio da Paz de Vestfália ou do Tratado de Vestfália, em 1648, momento em que "o Estado moderno já está fortemente amparado por sólida estrutura política, econômica e militar" (Bedin, 2011, p. 24). Nesse ano foram assinados dois tratados: um na Cidade de Munster (entre os príncipes protestantes) e outro na Cidade de Osnabruck (entre os príncipes católicos), ficando definido que os direitos do papa e do imperador seriam definitivamente restringidos em favor dos Estados. Ou seja, a regra de Vestfália significa que na região (território) sob império de um príncipe vigeria unicamente uma ordem jurídica.

Assim, surge na Paz de Vestfália a sociedade internacional clássica, pois reconheceu o Estado moderno como poder soberano dentro de suas fronteiras, sem interferências transnacionais das autoridades políticas da igreja e do império. Dessa forma, o Estado, que era soberano, passava a ser o ponto de referência das relações internacionais (Bedin, 2011).

\subsection{A Declaração de Virgínia}

Segundo José Afonso da Silva (2003), a primeira declaração de direitos fundamentais, em sentido moderno, foi a Declaração de Direitos do Bom Povo de Virgínia, que era uma das treze colônias inglesas da América. Isso porque representou a positivação dos direitos fundamentais, vinculando governo e governado de forma efetiva.

Essa declaração, datada de 12.01.1776, foi anterior à Declaração de Independência dos Estados Unidos, mas ambas foram inspiradas nas teorias de Locke, Rousseau e Montesquieu, sendo versadas especialmente nos escritos de Jefferson e Adams e postas em prática por James Madison, George Mason e outros tantos.

Segundo Comparato (2010), a constituição teve um estilo mais retórico do que técnico jurídico, refletindo a mentalidade puritana que predominava nas colônias norte-americanas, pois as regras de direitos eram consideradas indisso- 
lúveis da moralidade pessoal. Ela assegurava que todos os seres humanos, pela sua própria natureza, são igualmente livres e independentes, o que foi reafirmado em 1789 na declaração dos direitos do homem e em 1948 na declaração universal.

A Declaração de Virgínia expressa muito bem os fundamentos do regime democrático: o reconhecimento de "direitos inatos" de toda a pessoa humana, que não podem ser alienados ou suprimidos por uma decisão política, e o princípio de que todo o poder emana do povo, que possuem como subordinados os governantes. Também a Constituição de Virgínia se destaca pela proteção de liberdades, tais como liberdades religiosas e liberdades de imprensa, sendo que esta se torna um dos pilares da cidadania democrática norte-americana.

Assim, a Declaração de Virgínia consubstanciava as bases dos direitos do homem, preocupando-se com a estrutura de um governo democrático e com um sistema de limitação de poderes.

\subsection{A deCLARaÇÃo de dIREITOS NORTE-AMERICANA}

A declaração de independência dos EUA ocorreu em 1776, quando as 13 colônias britânicas da América do Norte tornaram-se independentes, sob forma de uma confederação; em seguida, constituídas em um Estado Federal, em 1787. Segundo Comparato (2010, p. 111), "representou o ato inaugural da democracia moderna, combinando, sob um regime constitucional, a representação popular com a limitação de poderes governamentais e o respeito aos direitos humanos".

Todavia, conforme Silva (2003), a Constituição Americana aprovada na Convenção de Filadélfia, em 17.09.1787, não continha inicialmente uma declaração dos direitos fundamentais do homem, e sua entrada em vigor dependia da ratificação de pelo menos nove dos treze Estados independentes. Entretanto, alguns somente concordavam em aderir ao pacto se fosse introduzida na Constituição uma Carta de Direitos, na qual se garantissem os direitos fundamentais do homem, o que foi feito por Thomas Jefferson e James Madison, por meio de emendas à Constituição de Filadélfia, aprovadas em 1791, às quais se acrescentaram outras até 1975, constituindo o Bill of Rights do povo americano, assegurando diversos direitos fundamentais.

Conforme Comparato (2010, p. 123), os "bill of rights norte-americanos são, essencialmente, declarações de direitos individuais. O pensamento político-jurídico norte-americano permaneceu, aliás, até hoje, vinculado a essa fase histórica, sem aceitar a evolução posterior, no sentido da afirmação dos direitos sociais e dos direitos humanos da humanidade". Todavia, os norte-americanos elevaram seu patrimônio cultural, transformando os direitos naturais em direitos positivos, reconhecendo-os como superior aos demais. Dessa forma, seguindo o modelo da Declaração de Direitos Inglesa, os Estados Unidos deram aos direi- 
tos humanos a qualidade de direitos fundamentais, ou seja, reconhecidos pelo Estado, sendo elevados a nível constitucional.

\subsection{A Declaração dos Direitos do Homem e do Cidadão}

A Declaração dos Direitos do Homem e do Cidadão, de 26 de agosto de 1789, é considerada, por Manoel Gonçalves Ferreira Filho (1999), a mais famosa das declarações, por ter sido por um século e meio o modelo por excelência das declarações, merecendo, ainda hoje, respeito e reverência daqueles que se preocupam com a liberdade e os direitos do homem.

Ela representa o atestado de óbito do antigo regime, que se assentava sobre a monarquia absoluta e os privilégios feudais, e a instauração da ordem burguesa na França, sendo o primeiro elemento constitucional do novo regime político.

Segundo Comparato (2010), a explicação mais razoável para o título da declaração (homem e cidadão) era de que os homens de 1789 não se dirigiam apenas ao povo francês, mas a todos os povos, concebendo uma dupla concepção ao documento: nacional e universal. Na Constituição de 1791 é esclarecida essa distinção, contendo nas "disposições fundamentais" que "direitos do homem" seriam independente de sua nacionalidade e os "direitos do cidadão" eram próprios unicamente dos franceses.

Nesse primeiro texto de 1789 , as liberdades individuais alcançaram uma definitiva precisão de contornos, e, como salientou Marx, a revolução burguesa desencadeou o mais rápido movimento de transformação social de todos os tempos.

Tanto a declaração francesa quanto as declarações americanas tinham como característica comum sua profunda inspiração jusnaturalista, reconhecendo ao ser humano direitos naturais, inalienáveis, invioláveis e imprescritíveis, direitos de todos os homens (universais), e não apenas de um estamento ou casta.

A Declaração Francesa de 1789 era mais abstrata, mais "universalizante", possuindo como caracteres fundamentais o intelectualismo, o mundialismo e o individualismo. Conforme José Afonso da Silva:

O texto da Declaração de 1789 é de estilo lapidar, elegante, sintético, preciso e escorreito, que, em dezessete artigos, proclama os princípios da liberdade, da igualdade, da propriedade e da legalidade e as garantias individuais que ainda se encontram nas declarações contemporâneas, salvas as liberdades de reunião e de associação que ela desconhecera, firmado que estava numa rigorosa concepção individualista. (2003, p. 158)

Outro ponto importante da Declaração de 1789, segundo Carvalho (2002), foi o fato dela erigir como fundamento a origem popular do poder, ou 
seja, o poder seria, a partir daí, concebido não mais como um direito divino dos reis, mas como a expressão da vontade geral do conjunto de cidadãos. Todavia, as concepções burguesas derivadas da revolução francesa conceberam uma soberania popular limitada, pois nem todos os membros do povo alcançavam o direito de participar do processo político, sendo que para proteger a classe dos proprietários foi estabelecido o voto censitário e a mulher não tinha o direito de votar.

Assim, verifica-se que a igualdade estabelecida pela revolução francesa foi uma igualdade meramente jurídica e de natureza formal, mas, sem dúvida, foi um imenso avanço, pois até aquele período sequer havia igualdade jurídica, visto que vigorava o regime de estamentos. Dessa forma, Carvalho (2002) segue afirmando que o espírito da revolução francesa estabeleceu as condições da democracia moderna, a doutrina do constitucionalismo e o Estado de poderes limitados, sendo que os revolucionários estavam imbuídos de um ideal de universalidade e a revolução francesa constituiu-se em um marco referencial da doutrina dos direitos do homem, espraiando sua força por toda a Europa e por outros continentes do globo terrestre.

\subsection{A carta das Naç̄óes Unidas}

Enquanto na Primeira Guerra Mundial se almejavam conquistas territoriais, sem, no entanto, escravizar ou destruir os povos inimigos derrotados, a Segunda Guerra Mundial é instigada em função de ideais de povos considerados superiores. Esta guerra iniciou com a invasão da Polônia pelas forças nazistas alemãs, em 1939, e teve o seu marco final marcado pelos lançamentos das bombas atômicas nas Cidades de Hiroshima e Nagasaki, no Japão, em agosto de 1945, demonstrando o poder de destruição que está nas mãos dos homens.

Com isso, os povos passaram a ver que a sobrevivência humana depende da cooperação e colaboração de todos e de uma reorganização das relações internacionais, com respeito absoluto à dignidade humana.

Assim, em 1945 surge a Organização das Nações Unidas (ONU), a qual se distingue da Sociedade das Nações, pois, em 1919, com o término da Primeira Guerra Mundial, buscou-se criar instâncias de arbitragem e regular os conflitos bélicos. Em 1945, busca-se pôr fim à guerra definitivamente colocando-a fora da lei.

Frente ao poderio destruidor dos Estados totalitários, sobre os demais povos, levantou-se a questão da necessidade de respeito aos direitos humanos, para buscar a convivência pacífica das nações, pois sem respeito tal convivência será impossível (Comparato, 2010). Nesse sentido, as Nações Unidas surgem para organizar a sociedade política mundial, devendo pertencer à Organização todos os países que lutam pela defesa e respeito da dignidade da pessoa humana. 
A carta de fundação da ONU foi assinada por 51 países, em 26 de junho de 1945, após a Conferência de São Francisco. Os arts. 13 e 55 da carta são claros ao referir que os direitos humanos são liberdades individuais. Observa-se que, conforme Comparato (2010), a tarefa principal e um dos principais propósitos da ONU é manter a paz e a segurança internacional, o que, de certa forma, não tem sido cumprido como o esperado, frente a composição oligárquica do Conselho de Segurança, uma vez que os membros permanentes possuem o poder do veto. Uma das principais funções do Conselho, prevista no art. 26, é a de formular "os planos a serem submetidos aos membros das Nações Unidas, para o estabelecimento de um sistema de regulamentação de armamentos", no entanto, tal tarefa nunca foi respeitada, frente aos propósitos nacionais das grandes potências.

Em virtude dos abusos cometidos pelo conselho de segurança, não tem funcionado de forma plausível o sistema de solução pacífica de controvérsias, previsto no capítulo IV da carta. As controvérsias de caráter jurídico deveriam ser submetidas obrigatoriamente à Corte Internacional de Justiça, com sede em Haia, conforme art. 36. No entanto, quando a solução do conflito não é favorável para os membros do Conselho de Segurança, o mesmo não permite que o recurso chegue à Corte Internacional de Justiça, resolvendo o conflito da maneira que mais Ihes convêm, até com o uso do poderio militar.

\subsection{A Declaração Universal dos Direitos Humanos}

A Comissão de Direitos Humanos, órgão pertencente à ONU, em 18 de junho de 1948, concluiu o projeto de Declaração Universal dos Direitos Humanos, tendo sido aprovado pela Assembleia Geral das Nações Unidas, em 10 de dezembro do respectivo ano. A Declaração, de certa forma, busca revitalizar o lema da Revolução Francesa a nível universal, reconhecendo os valores supremos da igualdade, da liberdade e da fraternidade.

A Declaração Universal dos Direitos Humanos, conforme se vislumbra no seu preâmbulo, foi elaborada em meio ao choque das barbáries vivenciadas durante a Segunda Guerra Mundial, suprimindo-se questões relativas à União Soviética e aos excessos praticados pelas potências ocidentais após o encerramento dos conflitos. Nem todo o conteúdo previsto na carta foi aceito por todos os países membros. Embora o documento tenha sido aprovado por unanimidade, os países comunistas, a Arábia Saudita e a África do Sul se abstiveram de votar.

Ela é uma recomendação que a Assembleia Geral das Nações Unidas faz aos seus membros, ou seja, a declaração não possui força vinculante. No entanto, atualmente, a validade dos direitos humanos é reconhecida em todas as partes, independente de declarações, constituições, leis ou tratados internacionais, uma vez que se busca o respeito à dignidade da pessoa humana. Ademais, os direitos elencados na declaração são reconhecidos internacionalmente como 
normas imperativas de direito internacional geral. Esse também é o entendimento da Corte Internacional de Justiça.

Verifica-se, assim, nos dizeres de Comparato (2010), que a Declaração Universal dos Direitos Humanos sem dúvida é a maior conquista e reconhecimento dos Direitos Humanos, teve seu início com a Declaração de Independência dos Estados Unidos e a Declaração dos Direitos do Homem e do Cidadão, da Revolução Francesa, na qual foi reconhecido que todos são iguais em liberdade e dignidade, independente de raça, cor, sexo, língua, religião, opiniões, posição social, situação econômica. Esse reconhecimento ocorre com o fim da Segunda Guerra Mundial, quando ficou claro que a ideia de superioridade de raça, cor, religião e cultura sobre os demais povos coloca em perigo toda vida humana existente na Terra.

Em relação ao seu teor, cabe salientar que a declaração, no seu artigo I, institui os três princípios fundamentais dos direitos humanos: a liberdade, a igualdade e a fraternidade. A Declaração Universal dos Direitos Humanos garantiu as liberdades individuais clássicas e reconheceu os direitos políticos. Entre várias outras determinações, a declaração também afirmou ser o regime democrático o único sistema político compatível ao respeito dos direitos humanos (artigos XXI e XXIX, alínea 2).

Conforme menciona Carvalho (2002, p. 46), "em razão de trazer em seu bojo os direitos civis e políticos ao lado dos direitos econômicos, culturais e sociais, podemos dizer que a Declaração dos Direitos do Homem adotou a concepção da indivisibilidade e interdependência dos direitos humanos". Tal afirmação é complementada por Flávia Piovesan (2012), ao afirmar que:

[...] sem a efetividade dos direitos econômicos, sociais e culturais, os direitos civis e políticos se reduzem a mera categorias formais, enquanto que, sem a realização dos direitos civis e políticos, ou seja, sem a efetividade da liberdade entendida em seu mais amplo sentido, os direitos econômicos, sociais e culturais carecem de verdadeira significação. Não há mais como cogitar da liberdade divorciada da justiça social, como também infrutífero pensar na justiça social divorciada da liberdade. Em suma, todos os direitos humanos constituem um complexo integral, único e indivisível, em que os diferentes direitos estão necessariamente inter-relacionados e são interdependentes entre si. (Piovesan, 2012, p. 209-210)

\subsection{Convençōes E PACTOS DE DIREITOS HUMANOS}

Seguindo-se a evolução dos direitos humanos, com foco no acesso à Justiça, para se chegar ao seu conceito atual, verifica-se a importância das convenções e pactos de direitos humanos, com destaque para a Convenção Europeia, os Pactos Internacionais de 1966 e a Convenção Americana de Direitos Humanos, que serão analisados a seguir. 


\subsubsection{A Convenção Europeia dos Direitos Humanos}

A Convenção para a Proteção dos Direitos Humanos e das Liberdades Fundamentais foi celebrada em 1950 pelo Conselho da Europa, limitando seu alcance aos direitos individuais clássicos, o que representa, nesse aspecto, um recuo em relação à Declaração Universal dos Direitos Humanos, invocada em seu preâmbulo. Contudo, a Convenção Europeia de 1950 ampliou sobremaneira as medidas tradicionais de proteção da liberdade e da segurança pessoal.

Convém salientar, ainda, que, segundo Comparato (2010), a grande contribuição da Convenção Europeia foi, de um lado, a instituição de órgãos incumbidos de fiscalizar o respeito aos direitos nela declarados e julgar suas eventuais violações pelos Estados signatários e, de outro lado, o reconhecimento do indivíduo como sujeito de direito internacional, no que tange à proteção dos direitos humanos.

A convenção previa também um órgão intermediário entre o queixoso e o Tribunal Europeu de Direitos Humanos, ou seja, a Comissão de Direitos Humanos, encarregada da triagem das denúncias, da investigação dos fatos e da manifestação de opinião fundada sobre a ocorrência ou não de violações. As denúncias podiam ser apresentadas pelos Estados-parte, por qualquer pessoa, por organização não governamental ou por grupo de indivíduos. Entretanto, apenas eram recebidas as denúncias contra um Estado que houvesse previamente reconhecido a competência da comissão para processá-las. Posteriormente a comissão foi extinta e a competência transferida ao Tribunal.

Em relação ao acesso à Justiça, cabe mencionar que a Convenção Europeia de Direitos Humanos foi o primeiro documento de alcance internacional a reconhecer o direito à efetiva e pronta prestação jurisdicional, visto que em seu art. $6^{\circ}$, I, dispõe, desde 1950, que todo indivíduo tem o direito à prestação jurisdicional em prazo razoável.

\subsubsection{Os Pactos Internacionais de Direitos Humanos de 1966}

A Declaração Universal de Direitos Humanos, aprovada em 1948, tomou o formato de manifesto, destituída, pois, de força jurídica obrigatória, diversamente do que acontece com os tratados (convenções, pactos e acordos). Nesse sentido, prevaleceu, conforme Flávia Piovesan (2012), o entendimento de que a declaração deveria ser "juridicizada", sob a forma de tratado internacional, tornando-se juridicamente obrigatória e vinculante no âmbito do direito internacional. Daí a necessidade de elaboração de outro documento, na forma de tratado, dotado de força jurídica obrigatória no respeito aos direitos nela consagrados, inclusive, com previsão de um sistema de controle para assegurar sua implementação.

A "juridicização" da declaração iniciou em 1949, somente sendo concluída em 1966, com a elaboração de dois pactos, tratando cada qual de ca- 
tegorias de direitos específicos (um dos direitos civis e políticos e outro dos direitos econômicos, sociais e culturais), que deveriam, contudo, ser adotados e abertos à adesão simultaneamente, e passaram a incorporar os direitos constantes da Declaração Universal.

Os dois pactos, juntamente com a Declaração Universal dos Direitos Humanos, formam, portanto, o chamado Internacional Bill of Rights (declaração internacional de direitos), completando-se a etapa de institucionalização dos direitos humanos no âmbito internacional.

A divisão de direitos em dois pactos se mostra artificial, na medida em que os direitos humanos constituem um complexo integral, único e indivisível. Apesar de tratados em documentos diferentes, os direitos mantêm a unidade e interdependência. Tanto é assim que o preâmbulo de ambos os pactos é idêntico. Nesse sentido, não há como cogitar da liberdade divorciada da justiça social, como também infrutífero é pensar na justiça social divorciada da liberdade.

Essa unidade essencial do sistema de direitos humanos foi, aliás, afirmada pela Resolução no 32/120 da Assembleia Geral da ONU, em 1968, e confirmada pela Conferência Mundial dos Direitos Humanos, de 1993, na Declaração de Viena, ao afirmar, em seu $\S 5^{\circ}$, que os direitos humanos são universais, indivisíveis, interdependentes e inter-relacionados.

Em relação ao Pacto Internacional de Direitos Civis e Políticos, em vigor desde 23.03.1976, salienta-se que referido pacto reproduz a maioria dos direitos já consagrados na Declaração Universal dos Direitos Humanos, introduz outros direitos e também institui um órgão de monitoramento do cumprimento dos direitos consagrados nesses documentos pelos Estados-partes. Quanto aos direitos e liberdades cobertos pelo pacto, interessa para o presente estudo fazer referência especialmente ao art. 14, que trata do direito a julgamento justo, sendo que na sua alínea 1 vem consagrado o princípio do livre acesso aos órgãos judiciários e a garantia da assistência judiciária gratuita a pessoa carente.

Em relação ao Pacto Internacional sobre Direitos Econômicos, Sociais e Culturais, observa-se que o mesmo foi criado como um meio de defesa dos indivíduos e dos grupos sociais contra os privilégios e o abuso do poder estatal, ou melhor, luta contra a dominação de classe. O elemento comum ao conjunto de direitos nele declarados é a proteção das classes ou grupos sociais desfavorecidos, contra a dominação socioeconômica exercida pela minoria rica e poderosa. Antes o Estado era o sujeito passivo da relação jurídica, agora muda de polo, pois as violações de direitos, nesse aspecto, acontecem devido às interferências abusivas do Poder Público na vida privada e no exercício dos direitos políticos.

Como já reverenciado, os direitos humanos que compõe os dois pactos formam um conjunto indissociável. A liberdade individual é ilusória se não 
houver o mínimo de igualdade social, sendo, pois, o princípio da solidariedade o fecho de todo o sistema de direitos humanos.

\subsubsection{A Convenção Americana de Direitos Humanos}

Aprovada em 22.11.1969, na Conferência de São José da Costa Rica, a Convenção Americana de Direitos Humanos, também conhecida como Pacto de San José da Costa Rica, reproduz grande parte dos direitos constantes no Pacto Internacional de Direitos Civis e Políticos (1966). Com o intuito de obter a adesão dos EUA, a convenção não incluiu os direitos econômicos, sociais e culturais, bem como a abolição da pena de morte.

Alguns elementos trazidos pela convenção, no entanto, configuram um avanço com relação ao Pacto de 1966, aplicando-se, nesse caso, o

princípio da prevalência dos direitos mais vantajosos para a pessoa humana, ou seja, na vigência simultânea de vários sistemas normativos - o nacional e o internacional - ou na de vários tratados internacionais, em matéria de direitos humanos, deve ser aplicado aquele que melhor protege o ser humano. (Comparato, 2010, p. 380)

Observa-se que, nos Estados federativos, frequentemente é dificultado o respeito às normas internacionais de direitos humanos, pois dependendo do nível de autonomia dos entes federados, o Estado não possui meios para garantir a observância dos Direitos Humanos dentro de suas unidades territoriais. Já em relação à organização dos órgãos responsáveis pela verificação do cumprimento da convenção, o texto americano aproxima-se do texto da Convenção Europeia de 1950, e não do Pacto de 1966. No entanto, com relação à formulação de denúncias, afastou-se do texto europeu, assegurando a legitimidade de pessoas (individualmente ou em grupo), bem como de entidades da sociedade civil, para a propositura de demandas à comissão. Ademais,

ela criou, além de uma comissão encarregada de investigar fatos de violação de suas normas, também um tribunal especial para julgar os litígios daí decorrentes, a Corte Interamericana de Direitos Humanos, cuja jurisdição, no entanto, só é obrigatória para os Estados-partes que aceitem expressamente. (Comparato, 2010, p. 384)

Em relação ao Protocolo Adicional de 1988, referente aos direitos econômicos, sociais e culturais, contendo várias disposições inovadoras relativamente ao Pacto de 1966, verifica-se a pouca seriedade dos Estados que o aderiram. Especialmente porque à época já predominava a implementação de políticas neoliberais na América Latina e consequente falta de cumprimento dos direitos elencados.

Quanto a questão do acesso à Justiça, no mesmo caminho da Convenção Europeia, a Convenção Americana de Direitos Humanos (Pacto de São José da 
Costa Rica), preceitua desde 1969, em seu art. 8º , I, que todo indivíduo tem direito fundamental à prestação jurisdicional sem dilações indevidas.

\section{CONCEPÇ̃̃O ATUAL DO ACESSO À JUSTIÇA}

Segundo Cintra et al. (2004, p. 33), "o processo deve ser manipulado de modo a propiciar às partes o acesso à Justiça, o qual se resolve, na expressão muito feliz da doutrina brasileira recente, em acesso à ordem jurídica justa". E essa expressão "acesso à Justiça" tem uma difícil definição, pois abrange todos os meios a que se destina a um fim, a saber: a reivindicação dos direitos dos cidadãos e a solução dos litígios dos indivíduos, por meio de um sistema que deve proporcionar e produzir a todos resultados justos (Cappelletti; Garth, 1988, p. 8).

Percebe-se que, segundo Cappelletti e Garth (1988, p. 9-11), o conceito de acesso à Justiça sofreu uma transformação importante na passagem dos Estados liberais burgueses dos séculos XVIII e XIX, que tinham procedimentos para solução de litígios com caráter individualista, para as sociedades modernas, nas quais as ações e relacionamentos assumiram caráter mais coletivo, visto que passaram a reconhecer os direitos e deveres sociais dos governos, comunidades, associações e indivíduos. Dessa forma, a atuação positiva do Estado passou a ser necessária para assegurar o gozo desses direitos sociais básicos e o direito ao acesso efetivo à Justiça ganhou corpo na medida em que as reformas do Estado de bem-estar social procuraram conceder aos indivíduos novos direitos.

Atualmente, prevalece, nos dizeres de Cappelletti e Garth, o acesso à Justiça como requisito fundamental. Nesse sentido:

O direito ao acesso efetivo tem sido progressivamente reconhecido como sendo de importância capital entre os novos direitos individuais e sociais, uma vez que a titularidade de direitos é destituída de sentido, na ausência de mecanismos para sua efetiva reivindicação. $\mathrm{O}$ acesso à Justiça pode, portanto, ser encarado como o requisito fundamental - o mais básico dos direitos humanos - de um sistema jurídico moderno e igualitário que pretenda garantir, e não apenas proclamar os direitos de todos. (Cappelletti; Garth, 1988, p. 11-12)

Cita-se, nos dizeres de Cappelletti e Garth (1988, p. 13) que "o 'acesso' não é apenas um direito social fundamental, crescentemente reconhecido; ele é, também, necessariamente, o ponto central da moderna processualística. Seu estudo pressupõe um alargamento e aprofundamento dos objetivos e métodos da moderna ciência jurídica".

Percebe-se que o acesso à Justiça não é mais tido como a mera admissão do indivíduo ao processo ou possibilidade de ingresso ao juízo, pois de nada adianta permitir ao cidadão o seu acesso e não dar condições para que se obtenha uma sentença justa, eficaz e um processo imparcial. Nesse sentido, com a evolução na busca da melhor maneira de garantir a justiça para todos, a 
tendência moderna está desenvolvendo as ideias do direito social como forma de acesso por meio dos direitos fundamentais de ação e defesa, dentro de um Estado social, no qual a função fundamental do Estado é de promover a plena realização dos valores humanos e que, segundo Cintra et al.,

[...] deve servir, de um lado, para pôr em destaque a função jurisdicional pacificadora como fator de eliminação dos conflitos que afligem as pessoas e thes trazem angústia; de outro, para advertir os encarregados do sistema, quanto à necessidade de fazer do processo um meio efetivo para a realização da justiça. Afirma-se que o objetivo-síntese do Estado contemporâneo é o bem-comum e, quando se passa ao estudo da jurisdição, é lícito dizer que a projeção particularizada do bem comum nessa área é a pacificação com justiça. (Cintra et al., 2004, p. 25)

Nesse sentido, na lição de Cintra et al. (2004, p. 33), temos que: "[...] para que haja o efetivo acesso à Justiça é indispensável que o maior número possível de pessoas seja admitido a demandar e a defender-se adequadamente [...] mas, para a integralidade do acesso à Justiça, é preciso isso e muito mais". Assim, ao continuar, referem os autores que o acesso à Justiça é:

[...] a idéia central a que converge toda a oferta constitucional e legal desses princípios e garantias. Assim, (a) oferece-se a mais ampla admissão de pessoas e causas ao processo (universalidade da jurisdição), depois (b) garante-se a todas elas (no cível e no criminal) a observância das regras que consubstanciam o devido processo legal, para que (c) possam participar intensamente da formação do convencimento do juiz que irá julgar a causa (princípio do contraditório), podendo exigir dele a (d) efetividade de uma participação em diálogo-, tudo isso com vistas a preparar uma solução que seja justa, seja capaz de eliminar todo resíduo de insatisfação. Eis a dinâmica dos princípios e garantias do processo, na sua interação teleológica apontada para a pacificação com justiça. (Cintra et al., 2004, p. 33-34)

Todavia, embora o acesso à Justiça tenha sido aceito como um direito social básico na sociedade moderna, ele carece de efetividade, considerando os obstáculos para alcançá-lo, entre os quais se destaca a demora do processo. E o interesse em torno do acesso efetivo à Justiça levou, segundo relatam Cappelletti e Garth (1988), a um movimento para soluções práticas, iniciado em 1965. A primeira onda desse movimento pretendia garantir a assistência judiciária gratuita para os pobres; a segunda, maior representatividade na defesa dos interesses difusos, especialmente nas áreas de proteção ambiental e do consumidor; a terceira, mais recente, dá um novo enfoque ao "acesso à Justiça", modificando o foco para o cidadão e, além de incluir os movimentos anteriores, vai além, na tentativa de atacar os obstáculos de modo mais articulado e compreensivo, encorajando a realização de reformas, incluindo:

[...] alterações nas formas de procedimento, mudanças nas estruturas dos tribunais ou a de novos tribunais, o uso de pessoas leigas ou para profissionais, tanto como juízes quanto como defensores, modificações no direito substantivo des- 
tinadas a evitar litígios ou facilitar sua solução e a utilização de mecanismos privados ou informais de solução dos litígios. (Cappelletti; Garth, 1988, p. 71)

Assim, verifica-se que com essas reformas busca-se modificar a estrutura processual e física do judiciário, em busca da efetivação do direito à Justiça. E, de fato, a Constituição Federal de 1988 foi amplamente influenciada pelos movimentos sociais, visto que incorporou um conjunto amplo de garantias e direitos, razão pela qual foi proclamada como a "Constituição Cidadã". Assim, os direitos constitutivos da cidadania foram significativamente alargados, pois ao lado dos direitos tradicionais de natureza individual foram incorporados os direitos supra-individuais, ou sociais (Spengler; Neto, 2011).

E nessa perspectiva de direito fundamental de acesso à Justiça, verifica-se que, no Brasil, o principal parâmetro normativo é o princípio da proteção judiciária, também chamado, segundo José Afonso da Silva (2003), de princípio da inafastabilidade do controle jurisdicional, que combinando os princípios do devido processo legal (art. 5º, LIV), do contraditório e plenitude de defesa (art. $5^{\circ}, \mathrm{LV}$ ) e do direito de acesso à Justiça (art. 5ㅇ, XXXV) fecha o ciclo das garantias processuais. Salienta-se, todavia, que o princípio da proteção judiciária não deve ser concebido apenas na sua acepção institucional (direito formal de invocar a jurisdição), mas sim como um princípio garantidor, especialmente a fim de garantir do Judiciário o direito a uma resposta rápida, precisa e justa, capaz de assegurar resultados úteis.

Com tudo isso, observa-se que esse novo enfoque de acesso à Justiça traz a ideia de que o princípio da proteção judiciária constitui-se em um direito humano fundamental de acesso a uma ordem jurídica justa. E o acesso à Justiça é o garantidor de todos os demais direitos, pois em seu entorno convergem todos os princípios e garantias constitucionais, razão pela qual é uma maneira de assegurar a efetividade aos direitos de cidadania. Dessa forma, é um direito de suma importância, por ser um direito elementar do cidadão, pelo qual ocorre a materialização da cidadania e a efetivação da dignidade da pessoa humana.

\section{CONCLUSÃO}

Com o presente artigo, foi possível verificar a evolução do acesso à Justiça, que é entendido como um direito humano fundamental, verificando os marcos históricos de seu desenvolvimento, desde as antiguidades clássicas, passando pela contribuição do cristianismo e da Reforma Protestante. Também pelas cartas e declarações inglesas, a Declaração da Virgínia, a declaração de direitos norte-americana e dos direitos do homem e do cidadão. Após, pela Carta das Nações Unidas e a Declaração Universal dos Direitos Humanos, até se chegar nas convenções e pactos de direitos humanos e a atual concepção do acesso à Justiça. 
Nesse sentido, foi possível perceber que ao longo de sua evolução histórica, o direito de acesso à Justiça passou por significativas transformações, acompanhando a evolução dos direitos fundamentais, visto que ele é o direito fundamental básico, pois viabiliza a concretização dos demais direitos. Assim, deixou de ser um direito de cunho meramente formal, como o era durante o Estado Liberal, e passou a ser compreendido como um direito ao acesso efetivo a uma ordem jurídica justa.

Dessa forma, verificou-se que o acesso à Justiça vai além da garantia do acesso ao Judiciário, pois é necessário permitir ao cidadão não só o seu acesso, mas principalmente o gozo de seus direitos no plano concreto. E, assim, possibilitar as condições para que se obtenha uma sentença justa, célere, eficaz e um processo imparcial, atingindo-se a materialização da cidadania e a efetivação da dignidade da pessoa humana.

\section{REFERÊNCIAS}

BEDIN, Gilmar Antonio. A Idade Média e o nascimento do Estado moderno: aspectos históricos e teóricos. ljuí: Unijuí, 2008. 2011. A sociedade internacional clássica: aspectos históricos e teóricos. ljuí: Unijuí,

CANOTILHO, José Joaquim Gomes. Direito constitucional e teoria da constituição. 7. ed. Coimbra: Edições Almeida, 2003.

CAPPELLETTI, Mauro; GARTH, Brian. Acesso à justiça. Trad. e rev. Ellen Gracie Northfleet. Porto Alegre: Sérgio Antonio Fabris, 1988.

CARVALHO, Oscar de. Gênese e evolução dos direitos humanos fundamentais. Revista do Instituto de Pesquisas e Estudos: Divisão Jurídica. Bauru/SP: Instituição Toledo de Ensino de Bauru, n. 34(1996), p. 31- 52, 2002.

CINTRA, Antônio Carlos de Araújo; GRINOVER, Ada Pellegrini; DINAMARCO, Cândido Rangel. Teoria geral do processo. 20. ed. rev. e atual. São Paulo: Malheiros, 2004.

COMPARATO, Fábio Konder. A afirmação histórica dos direitos humanos. 7. ed. rev. e atual. São Paulo: Saraiva, 2010.

FERREIRA FILHO, Manoel Gonçalves. Direitos humanos fundamentais. 3. ed. rev. São Paulo: Saraiva, 1999.

PIOVESAN, Flávia. Direitos humanos e o direito constitucional internacional. 13. ed. rev. e atual. São Paulo: Saraiva, 2012.

SARLET, Ingo Wolfgang. A eficácia dos direitos fundamentais. 9. ed. Porto Alegre: Livraria do Advogado, 2007.

SILVA, José Afonso da. Curso de direito constitucional positivo. 22. ed. rev. e atual. São Paulo: Malheiros, 2003.

SPENGLER, Fabiana Marion; SPENGLER NETO, Theobaldo. O acesso à justiça como direito humano básico e a crise da jurisdição no Brasil. Scientia luris (UEL), v. 15, p. 53-74, 2011.

VENTURA, Deisy. Monografia jurídica: uma visão prática. 1. ed. Porto Alegre: Livraria do Advogado, 2000. 